\title{
JOINING ZONE EVALUATION OF HYBRID SEMI-FINISHED PRODUCTS AFTER BACKWARD CAN EXTRUSION
}

\author{
${ }^{1}$ Bernd-Arno BEHRENS, ${ }^{1}$ Johanna UHE, ${ }^{1}$ Tom PETERSEN, ${ }^{1}$ Phil DEMTER, \\ ${ }^{1}$ Christoph BÜDENBENDER, ${ }^{1}$ Ingo ROSS \\ ${ }^{1}$ Institute of Forming Technology and Machines, Leibniz University Hannover, Garbsen, Germany, EU, \\ behrens@ifum.uni-hannover.de, uhe@ifum.uni-hannover.de,petersen@ifum.uni-hannover.de, \\ phil.demter@stud.uni-hannover.de, buedenbender@ifum.uni-hannover.de, \\ Correspondence:ross@ifum.uni-hannover.de
}

https://doi.org/10.37904/metal.2021.4106

\begin{abstract}
As a result of the general need for lightweight product design, multi-material systems are gaining in importance. In addition to reducing component weight, the combination of different materials in a single component allows other properties to be locally tailored to its application. This topic is the aim of research within the Collaborative Research Centre (CRC) 1153 "Tailored Forming", which investigates the entire process chain for the production of hybrid components from previously joined workpieces. One of the main focal points is the investigation of the joining zone development of steel-aluminium products (20MnCr5 - EN AW-6082) during friction welding and further processing in different forming processes.

The overall strength of the multi-material component is determined by joint strength. In order to improve the properties of the joining zone by thermomechanical treatment, a backward can (BC) extrusion process was utilized. This work addresses both, the simulative design as well as the implementation of heating and forming processes for $\mathrm{BC}$ extrusion. The joint interface of the hybrid components was analysed and a qualitative evaluation was carried out using metallographic images. The simulation results were validated and an effect on the joining zone trough $\mathrm{BC}$ extrusion could be achieved.
\end{abstract}

Keywords: Tailored forming, backward can extrusion, hybrid components, forging simulation

\section{INTRODUCTION}

In order to cope with rising energy and resource costs as well as increased environmental responsibility, an efficient use of energy and materials is gaining in importance. Since conventional components made out of a single material have their material-specific limits, new material concepts and manufacturing technologies need to be developed continuously to conform to the steadily increasing requirements. In this context, multimaterial solutions represent a promising approach. A common method for producing hybrid parts is the joining of previously formed near-net-shape components. In contrast, the bulk metal forming of hybrid components allows the creation of complex joining zones in accordance with the load conditions of the part. However, further research is required [1].

The Tailored Forming approach, currently being developed in the Collaborative Research Centre 1153 (CRC 1153), shifts the joining process to the beginning of the process chain [2]. This relocation enables the manufacturer to utilize the subsequent production stages to adapt and enhance the joining zone. The creation of a hybrid semi-finished workpiece and subsequent handling throughout the process chain generates new process-specific challenges, especially since the joining zone is not supposed to be the weak spot. 


\section{STATE OF THE ART}

Within sheet metal forming, hybrid semi-finished products are already widely established $[3,4]$, whereas hybrid bulk metal forming products are not broadly used. There has been basic research by Domblesky et al. into the forging of welded billets [5]. It was demonstrated that bi-metal preforms friction-welded from copper, aluminium and steel can be forged using modified processes. Chemnitz Technical University showed in the Collaborative Research Center 692 that a bond between aluminium and magnesium alloys can be achieved through compound extrusion [6-8]. Foydl et al. developed a compound-extrusion process to create hybrid billets to forge connecting rods and the steel-aluminium joining zone remained intact [9]. Wang et al. numerically and experimentally investigated the hot upsetting of weld-cladded steel-steel billets [10]. Another joining concept for hybrid workpieces is joining through forging. Some material combinations, e.g. steel-aluminium, can form undesired brittle intermetallic phases in the joint during this production process [1]. Within the CRC 1153, friction welding was evaluated to bond hybrid semi-finished products.

Friction welding is a solid-state welding method. It depends on heat and plastic deformation to create a joint between the two welding partners. This is achieved through relative motion combined with applied pressure between two raw parts, which leads to heat generation on the contact surfaces. Material at the joining zone starts to flow outward and the workpieces shorten. Subsequently, the relative motion is abruptly stopped and the pressure applied between the two workpieces is increased. The high deformation, high compressive stress and recrystallisation result in grain refinement. During friction welding, intermetallic phases are formed. However, due to the low temperature and the outward material flow these stay comparatively thin [11]. These characteristics make friction welding appropriate for joining dissimilar materials in a reproducible and reliable quality [12].

Within the scope of this paper, extrusion processes were developed to improve the joining zone of a steelaluminium specimen. Extrusion is a solid forming process in which the material is forced to flow through a die. In most cases, impact extrusion is carried out at room temperature, as this offers advantages in terms of precision. Impact extrusion at high temperature lowers the required process forces and allows for a higher deformation of the workpieces without work hardening and cracking. This comes at the cost of lower surface quality and precision compared to cold impact extrusion [13]. The process is classified depending on the workpiece geometry (whole, hollow) and the material flow relative to the movement of the tool. There are three flow directions: forward, backward and lateral [14].

\section{TAILORED FORMING PROCESS CHAIN}

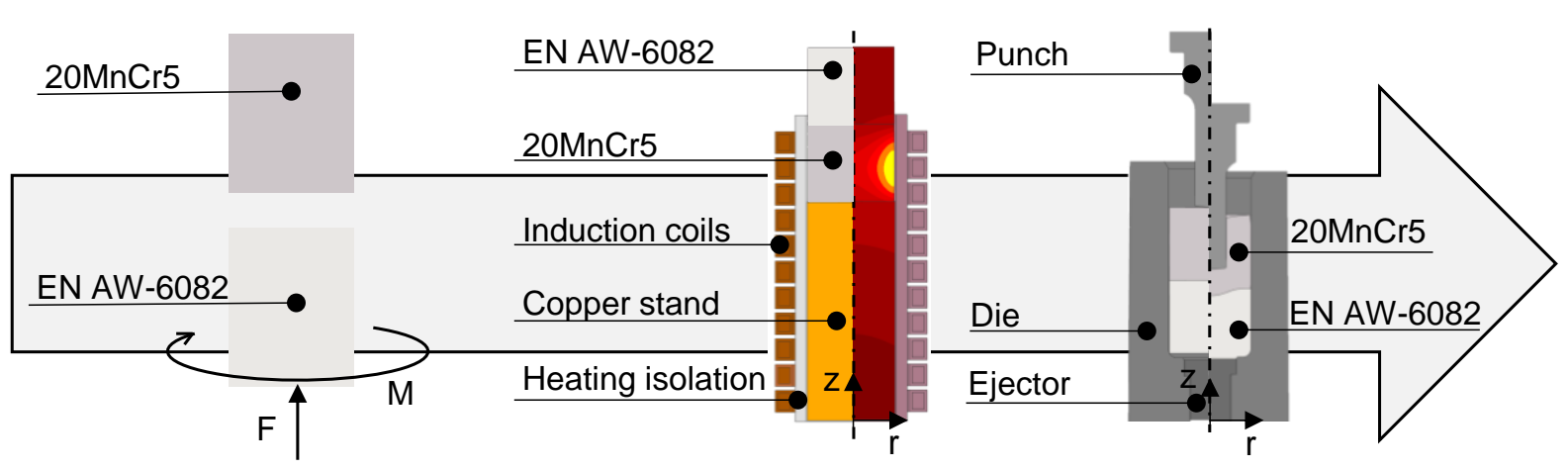

(a)

(b)

(c)

Figure 1 (a) Friction welding of aluminium and steel, (b) induction heating of the hybrid semi-finished product, (c) backward can extrusion

First, two different cylindrical bars were joined by friction welding. In order to achieve a temperature distribution of the hybrid semi-finished product that is suitable for forming, an induction heating process was designed 
numerically. The numerically determined process parameters were used in experimental induction heating tests. The process chain ends with backward can extrusion. The details of this process step were also designed numerically. With the help of the numerical modelling of the process chain, the temperature distribution of the hybrid semi-finished product was optimised. Furthermore, the proportions of aluminium and steel within the semi-finished product could be optimised for the subsequent forming process. Details of the process steps are presented in the following subchapters; Figure 1 shows the individual process steps.

\subsection{Friction Welding}

At first, serially arranged hybrid forging billets consisting of $20 \mathrm{MnCr} 5$ (AISI 5120) steel and EN AW-6082 (AA6082) aluminium alloy were joined by friction welding. In preparation, the respective joining surfaces were machined and degreased to create reproducible conditions. Subsequently, friction welding was carried out. The most important parameters are shown in Table 1.

Table 1 Parameters used for friction welding

\begin{tabular}{|c|c|c|c|c|}
\hline Billet diameter (mm) & Relative friction path (mm) & Frictional force (kN) & Press force (kN) & Press time (s) \\
\hline 40 & 4 & 150 & 251 & 2 \\
\hline
\end{tabular}

Using these parameters, it is primarily the aluminium that is deformed, while nearly no material flow is visible on the steel side. The flow of aluminium is utilized to dislocate impurities to the outside. Moreover, the short process time leads to a lower temperature in the material, which minimizes the creation of brittle intermetallic phases, which would have a negative impact on the joining zone [2].

Subsequently, the billet is cut to the required length of $70 \mathrm{~mm}$, with $35 \mathrm{~mm}$ of each steel and aluminium. In addition, the welding flash is removed by turning.

\subsection{Induction Heating}

Before forging, the steel part of the billet has to be heated to lower the difference in flow stress between steel and aluminium [2]. The steel and aluminium used would have the same flow stress at $900{ }^{\circ} \mathrm{C}$ and $20^{\circ} \mathrm{C}$, respectively. This temperature difference cannot be obtained because of the high thermal conductivity of aluminium. Therefore, the aim is to set a temperature gradient as steep as possible across the joining zone, which was determined by heating simulations and subsequently validated by experiments. An axial symmetric numerical model of the induction heating process was built up with the commercial FE-software Simufact.Forming v16. The process boundary conditions of the induction heating process, such as frequency and current in the induction coil, were designed in the range of a possible interval of the experimental setup. As numerically simulated, the heating was carried out using a $40 \mathrm{~kW}$ mid-frequency generator (TRUMPF TruHeat MF 3040), which can be operated in a frequency range between 5 and $30 \mathrm{kHz}$ coupled to a $40 \mathrm{~mm}$ diameter coil. The induction coil consists of 11 rectangular windings. The coaxial hybrid semi-finished product is placed in the induction coil so that only the steel part is completely enclosed by the coil as seen in Figure 1. The necessary electromagnetic material properties of the hybrid billet, as well as the current flow and heat generation of the coil were evaluated in [15]. The transport to the forming stage lasted five seconds, during which a further temperature exchange occurred in the hybrid semi-finished product. This was also considered in the model.

\subsection{Backward Can Extrusion}

In order to investigate the effect of different extrusion processes on the joining zone, a hollow demonstrator shaft (Figure 2 a) was designed which can be produced by the extrusion processes: backward can extrusion (b), forward tube extrusion (c) and combined forward rod and backward can (BC) extrusion (d). The BC extrusion was carried out using a LASCO SPR 500 screw press with $279 \mathrm{~mm} \cdot \mathrm{s}^{-1}$ impact velocity. The steel 
side of the billet was facing the punch and subsequently the punch permeated the billet to a depth of $30 \mathrm{~mm}$. After the extrusion, the workpiece was quenched in water.

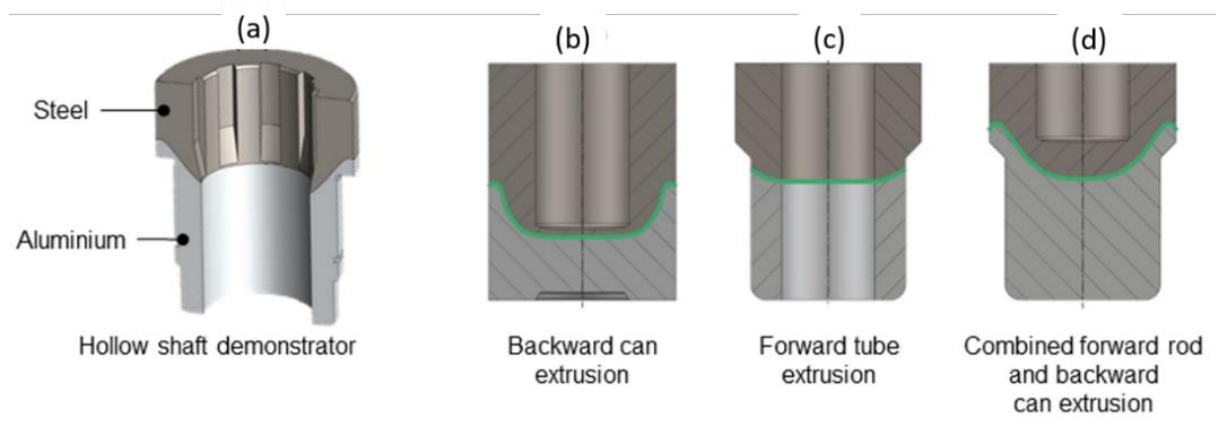

Figure 2 Hollow shaft demonstrator (a) and the impact extrusion preforms (b, c, d)

The BC extrusion process was also investigated numerically. The model created consists of a punch, a die and an ejector as seen in Figure 1. The hybrid semi-finished product was placed inside the die. The initial temperature distribution was taken from the induction heating step with transfer time taken into account. An elasto-plastic material model was used. The flow curves, which were implemented in the material model, are described in [16]. A prior evaluated combined friction model, which includes the formulation of Tresca with $m=0.2$ and Coulomb with $\mu=0.1$, was used [17].

\section{RESULTS AND DISCUSSION}

The numerically determined temperature-time curves were compared with experimental results. The measuring points of the thermocouples are displayed in Figure 3 (a). The resulting temperature-time curves are depicted in Figure $\mathbf{3}$ (b). Figure $\mathbf{3}$ (c) shows the simulated temperature distribution over the semifinished product. A current of $1150 \mathrm{~A}$ applied to the induction coil for 25 seconds promises a suitable temperature distribution in the hybrid semi-finished product according to the numerical design of the inductive heating. This temperature distribution could be repeated in the experimental results, which can be seen from the results of the thermocouple TCSteel, as a good agreement between experimental and numerical results was achieved here. In comparison to TC $\mathrm{Stee}_{\text {, }}$ the results of the experimental measurements by the thermocouples near the joining zone named $\mathrm{TC} \mathrm{Jz}$, Steel and $\mathrm{TC} \mathrm{Cz}_{\mathrm{J}}$, Aluminium show greater differences to the numerical prediction. However, the exact shape of the intermetallic phase and the associated heat transfer coefficient are not known. This explains the discrepancy between simulated and experimental results for the TCJz,Steel and TCJz,Aluminium thermocouples near the joining zones. However, the induction heating model was considered validated.

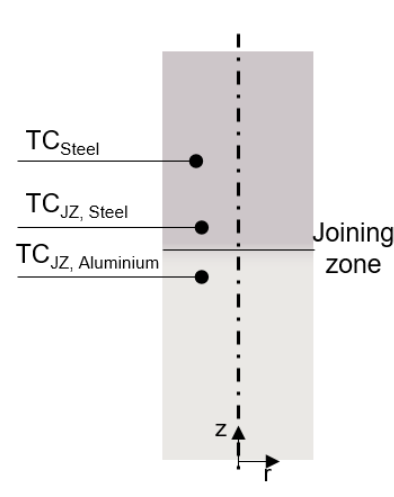

(a)

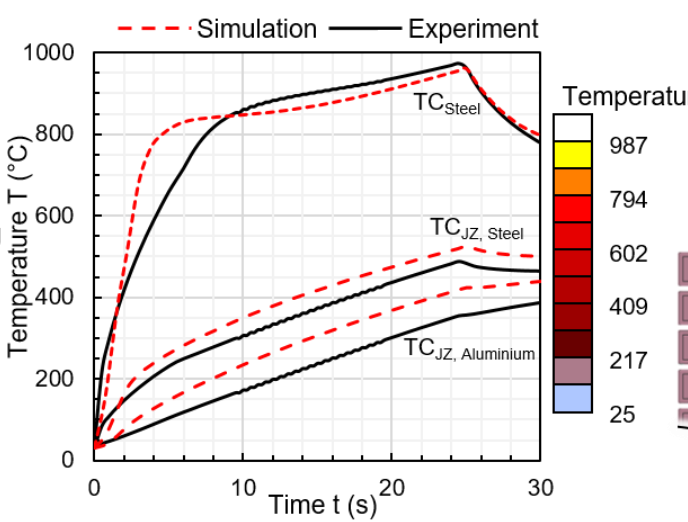

(b)

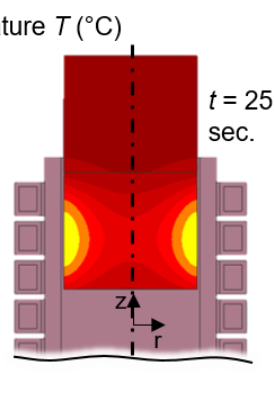

(c)

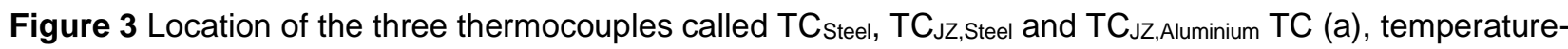
time curves (b), result of the numerically generated temperature distribution (c) 
Metallurgical investigations were carried out on cross-sectioned workpieces. Due to BC extrusion, the joining zone was significantly enlarged and a bulging shape was observed, which is shown in Figure 4 (a). In microscopic analysis, regions near the centre (region 1) or the edge (region 3) of the part show little cracking and mainly a sound bond between both metals. However, an increased concentration of cracks is observed in region 2. These cracks occurred in regions where tensile stresses have been predicted numerically, as depicted in Figure 4 (a). The cracks start on the aluminium side, with aluminium parts remaining on the steel in some areas, as can be seen in Figure 4 (b). Bulge height and slope are consistent with the simulated predictions.

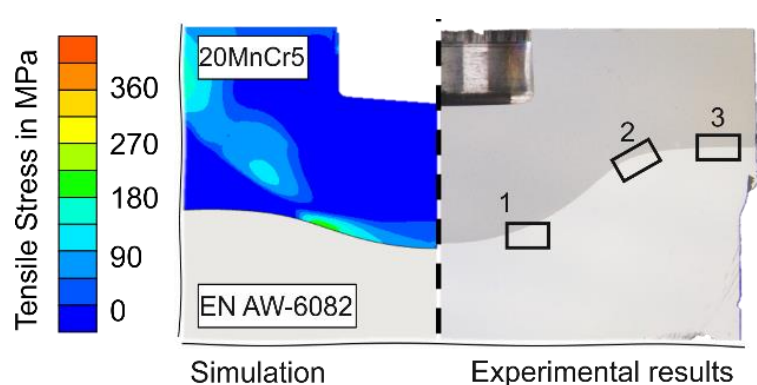

(a)

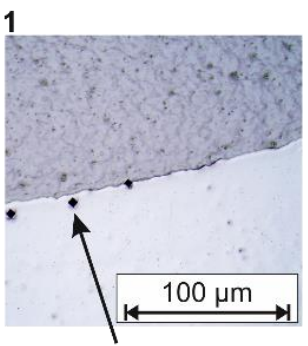

Hardness measuring points

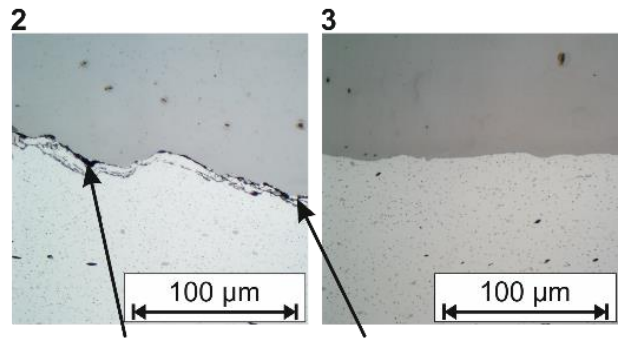

Cracks Aluminum residues on the steel (b)

Figure 4 Simulation and experimental results of the backward can extrusion process (a) and metallurgical images of the joining zone (b)

\section{CONCLUSION}

The limiting factor of hybrid steel-aluminium components is the strength of the joining zone, which fails prior to the base material due to brittle material properties. Previous experiments within the CRC 1153 have shown that the production of hybrid workpieces, using pre-joined billets, through full forward extrusion is possible [15]. However, the influence on the joining zone achieved by this process is limited. In order to improve the influence on the joining zone and to expand workpiece variety, other impact extrusion processes are investigated.

In the present study, the heating and forming of semi-finished hybrid products were investigated numerically and validated by experimental data. Therefore, semi-finished products prejoined by friction welding were formed by BC extrusion and investigated metallographically. The heating simulations agree with the measured values, especially on the steel side, but also near the joining zone. As seen in Figure 4 (a), the predicted joining zone geometry correlates with the experimental data. The simulation showed tensile stresses, which caused cracks in the deformed part of the joining zone. The aim of subsequent investigations is to increase the influence on the geometric and microstructural formation of the joining zone by means of an adapted heating strategy using aluminium-side immersion cooling. Additionally, further extrusion processes, namely forward tube extrusion (Figure $\mathbf{2} \mathbf{c}$ ), combined forward rod extrusion and backward can extrusion (Figure $\mathbf{2} \mathbf{d}$ ) will be investigated experimentally and numerically.

\section{ACKNOWLEDGEMENTS}

The results presented in this paper were obtained within the Collaborative Research Centre 1153 "Process chain to produce hybrid high performance components with Tailored Forming" funded by the Deutsche Forschungsgemeinschaft (DFG, German Research Foundation) - SFB 1153 TP-B3 252662854. The authors thank the DFG for the financial support of this project. In addition, the authors would like to thank subproject $C 1$ for the numerical simulations. 


\section{REFERENCES}

[1] KOSCH, K.-G., FRISCHKORN, C., HUSKIC, A., ODENING, D., PFEIFFER, I., PRÜSS, T., VAHED, N. Effizienter Leichtbau durch belastungsangepasste und anwendungsoptimierte Multimaterial-Schmiedebauteile. UTF Science. 2012, pp. 1-17.

[2] BEHRENS B.-A., UHE J., PETERSEN T., NÜRNBERGER, F., KAHRA, C., ROSS, I. LAEGER, R. Contact Geometry Modification of Friction-Welded Semi-Finished Products to Improve the Bonding of Hybrid Components. Metals. [online]. 2021, vol. 11, no. 1, p. 115. https://doi.org/10.3390/met11010115

[3] MERKLEIN, M., JOHANNES, M., LECHNER, M., KUPPERT, A. A review on tailored blanks - Production, applications and evaluation. Journal of Materials Processing Technology. 2014, vol. 214, no. 2, pp. 151-164.

[4] ZADPOOR, A. A., SINKE, J., BENEDICTUS, R. Mechanics of Tailor Welded Blanks: An Overview. Key Engineering Materials. 2007, vol. 344, pp. 373-382.

[5] DOMBLESKY, J., KRAFT, F., DRUECKE, B., SIMS, B. Welded preforms for forging. Journal of Materials Processing Technology. 2006, vol. 171-1, pp. 141-149.

[6] KITTNER, K., AWISZUS, B., LEHMANN, T., STOCKMANN M., NAUMANN, J. Numerische und experimentelle Untersuchungen zur Herstellung von stranggepressten Aluminium-/Magnesium-Werkstoffverbunden und zur Festigkeit des Interface. Materialwissenschaft und Werkstofftechnik. 2009, vol. 40, pp. 532-539.

[7] LEHMANN, T., STOCKMANN, M., KITTNER, K., BINOTSCH C.; AWISZUS, B. Bruchmechanische Eigenschaften von Al/Mg-Verbunden und deren Fließverhalten im Herstellungsprozess. Materia/wissenschaft und Werkstofftechnik. 2011, vol. 42, pp. 612-623.

[8] AWISZUS, B., NEUGEBAUER, R., KITTNER, K., POPP, M. Analyse des Querfließpressens als Analogieversuch zum Strangpressen unter besonderer Berücksichtigung der Verbundbildung zwischen Aluminium und Magnesium. [online]. IV/2009. Available from: www.utfscience.de.

[9] FOYDL, A., KOSCH, K.-G., JAEGER, A., PFEIFFER, I., TEKKAYA A. E., BEHRENS, B.-A. Co-Extrusion of Discontinuously Steel-Reinforced Aluminum. In: 6th JSTP International Seminar on Precision Forging. Kyoto, Japan, 2013, pp. 1-4.

[10] WANG, J., LANGLOIS, L., RAFIG, M., BIGOT R.; LU, H. Study of the hot forging of weld cladded work pieces using upsetting tests. Journal of Materials Processing Technology. 2014, vol. 214-2, pp. 365-379.

[11] FAHRENWALDT, HANS J. Schweißtechnik, Verfahren und Werkstoffe. Braunschweig/Wiesbaden: Friedr. Vieweg \& Sohn Verlagsgesellschaft $\mathrm{mbH}$, Braunschweig/Wiesbaden, 1994.

[12] PREUSS, M., WITHERS, P.J., BAXTER, G.J. A comparison of inertia friction welds in three nickel base superalloys. Material Science and Engineering A. 2006, vol. 437, pp. 38-45.

[13] TSCHÄTSCH, HEINZ. Praxis der Umformtechnik Arbeitsverfahren, Maschinen, Werkzeuge. Wiesbaden: Friedr. Vieweg \& Sohn Verlag/GWV Fachverlage GmbH, 2005.

[14] LANGE, KURT. Fließpressen Wirtschaftliche Fertigung metallischer Präzisionswerkstücke. Berlin Heidelberg: Springer-Verlag, 2008.

[15] BEHRENS, B.-A., WESTER, H., SCHÄFER, S., BÜDENBENDER, C. Modelling of an induction heating process and resulting material distribution of a hybrid semi-finished product after impact extrusion. In: ESAFORM 2021, 24th International Conference on Material Forming. Liège, 2021.

[16] BEHRENS, B.-A., CHUGREEV, A., MATTHIAS, T. Hybride Lagerbuchsen aus Aluminium und Stahl. wt Werkstatttechnik online. 2018, vol. 108, pp. 691-697.

[17] BEHRENS, B.-A., BOUGUECHA, A., BONK, C., MATTHIAS, T. Importance of material and friction characterization for FE-aided process design of hybrid bevel gears. In: AIP Conference Proceedings. [online]. 2017, vol. 1896, 190016. Available from: https://doi.org/10.1063/1.5008229 